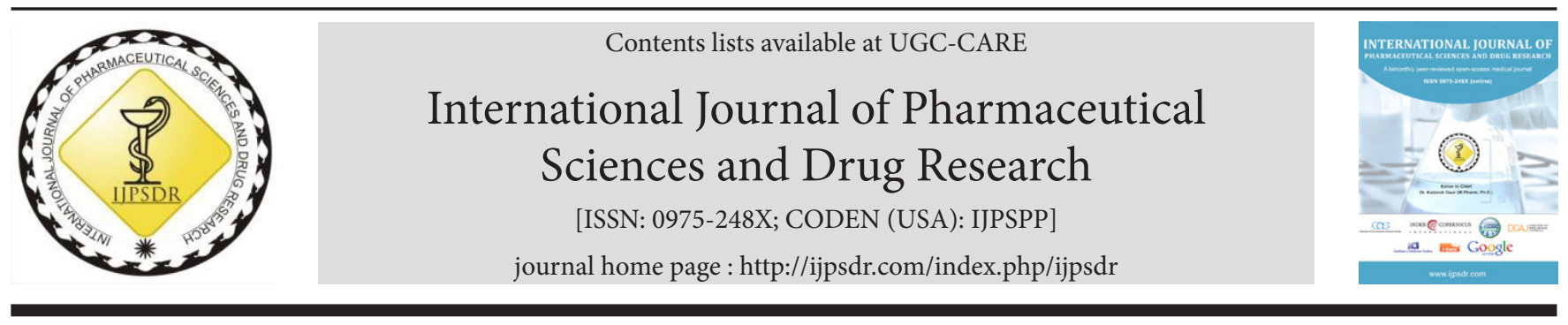

Research Article

\title{
Formulation Development of Rotigotine Transdermal System using Dot-Matrix Technology
}

\author{
Shailesh T. Prajapati ${ }^{1}$, Vipulbhai Mandli ${ }^{*}$ \\ ${ }^{1}$ Department of Pharmaceutics and Pharmaceutical Technology, Kalol Institute of Pharmacy, KIRC Campus, Ahmedabad-Mehsana Highway, \\ Kalol-382721, Gandhinagar, Gujarat, India \\ ${ }^{2}$ Department of Pharmaceutical Sciences, Hemchandracharya North Gujarat University, Patan-384265, Gujarat, India
}

\begin{tabular}{|c|c|}
\hline A R T I C L E I N F O & A B S T RACT \\
\hline $\begin{array}{l}\text { Article history: } \\
\text { Received: } 07 \text { May, } 2020 \\
\text { Revised: } 21 \text { June, } 2020 \\
\text { Accepted: } 30 \text { June, } 2020 \\
\text { Published: } 30 \text { July, } 2020 \\
\text { Keywords: } \\
\text { Central composite design, } \\
\text { Cold flow, } \\
\text { Dot-matrix technology, } \\
\text { Ex vivo skin permeation, } \\
\text { Pressure-sensitive adhesive, } \\
\text { Rotigotine. } \\
\text { DoI: } \\
\text { 10.25004/IJPSDR.2020.120414 }\end{array}$ & $\begin{array}{l}\text { The purpose of this research was to prepare and evaluate drug-in-adhesive type patches of rotigotine } \\
\text { using dot-matrix technology, which is the new generation of drug-in-adhesive transdermal delivery } \\
\text { system (TDS) that deliver drug therapy through less patch surface area and without compromising } \\
\text { adhesion. Preformulation studies, like solubility in permeation enhancers, compatibility study, transmission } \\
\text { study, uptake study, and crystallization study of rotigotine in various pressure-sensitive adhesive (PSA) } \\
\text { polymers were performed. Transdermal system was prepared by solvent casting method. Central composite } \\
\text { design (CCD) was chosen for optimization of the formulation. Design of experiment (DoE) was used to } \\
\text { study the impact of critical formulation parameters, like silicone adhesive concentration, povidone K29/32 } \\
\text { concentration, and propylene glycol concentration. Crystallization study of rotigotine in different PSAs } \\
\text { suggested that crystal inhibitor is required to load drugs above } 5 \% \text {. Selection of optimum batch was made } \\
\text { using a constraint-based graphical optimization technique. The optimum batch exhibited desired in vitro } \\
\text { adhesion parameters, like peel, tack, shear, and permeation rate, which is suitable for } 3 \text { days' wear properties } \\
\text { and desired permeation rate. The optimum batch was evaluated for appearance, weight of matrix, thickness, } \\
\% \text { assay of drug content, in vitro adhesion testing, cold flow study, and ex vivo skin permeation studies. } \\
\text { Backing film Scotchpak } 9730 \text { and release liner Scotchpak-1022 was selected based on transmission and } \\
\text { uptake study of rotigotine. Stability study indicates that developed formulation remains stable. The present } \\
\text { research confirms the feasibility of developing rotigotine transdermal system using novel technology. }\end{array}$ \\
\hline
\end{tabular}

\section{INTRODUCTION}

A TDS is proposed to release the medicine into systemic circulation through skin to cure disorders in locations far away from the site of application. Exact shape and size of TDS are available for systemic action and are proposed for the treatment or prevention of systemic disease. Medicine released from the TDS is absorbed through skin into blood circulation and reached to target tissues to achieve a therapeutic effect. ${ }^{[1]}$ TDS has many merits over conventional dosage forms; it will improves bioavailability, enhance therapeutic efficacy, avoid limitations of first-pass effect, and maintain steady plasma level of medicine. ${ }^{[2,3]}$
There are mainly two types of TDS, matrix type and reservoir type. Matrix type TDS contains drug in PSA, while reservoir type system may contain drug in solution or in PSA, but there is the rate-controlling membrane to manage the delivery of medicine ${ }^{[4,5]}$ Dot-matrix technique delivers the desired dose in low concentration and also reduces the size of the patch. Dot-matrix technique produces particles of drug-loaded polymer with very large surface area forming concentrated drug microcells in the polymer, which can hold a large amount of drug. This technique utilizes two polymers, i.e., acrylic polymer and silicone polymer. Firstly a highly concentrated drug solution is solubilized in acrylic polymer, and then the above solution

\footnotetext{
${ }^{*}$ Corresponding Author: Vipulbhai Mandli

Address: Department of Pharmaceutical Sciences, Hemchandracharya North Gujarat University, Patan-384265, Gujarat, India

Email $\square$ : vipul_mandli@yahoo.com

Tel.: +91-9898146888

Relevant conflicts of interest/financial disclosures: The authors declare that the research was conducted in the absence of any commercial or financial relationships that could be construed as a potential conflict of interest.

Copyright (C) 2020 Shailesh T. Prajapati et al. This is an open access article distributed under the terms of the Creative Commons AttributionNonCommercial-ShareAlike 4.0 International License which allows others to remix, tweak, and build upon the work non-commercially, as long as the author is credited and the new creations are licensed under the identical terms.
} 
is mixed with silicone polymer. The concentrated drug microcells of acrylic polymer are formed in the silicon polymer, and a high concentration gradient of drug is produced, causing efficient diffusion across the skin, so the size of the patch formulated remains very small, as compared to ordinary transdermal drug delivery systems (TDDS) patch. ${ }^{[6-10]}$ Rotigotine is a nonergolinic dopamine D3/D2/D1 receptor agonist delivered via a TDS, and has been evaluated for the treatment of idiopathic Parkinson's disease. ${ }^{[11]} \mathrm{A}$ transdermal patch formulation of the non-ergolinic dopamine agonist rotigotine (Neupro ${ }^{\circledR}$ ) is indicated as monotherapy for the treatment of early Parkinson's disease and as combination therapy with levodopa throughout the course of the disease. ${ }^{[12]}$ Neupro ${ }^{\circledR}$ transdermal patch of rotigotine is available as one-day application. The basic component of TDS is a backing film to support the adhesive matrix, PSAs as matrix to control the release, and provide adhesion properties to patch, rate controlling membrane for reservoir type patch, and a release liner to protect the patch during storage. ${ }^{[13]}$ In the present research study, dot-matrix technology was adopted for the development of TDS. Various preformulation studies, like solubility of the drug in various solvents and permeation enhancers, transmission and uptake study, drug-excipient compatibility study, and crystallization study in different type PSA were performed. CCD was chosen for the optimization of the formulation. DoE is used to study the impact of critical formulation parameters, like silicone adhesive concentration, povidone K29/32 concentration, and propylene glycol concentration. Selection of optimum batch was done using constraintbased graphical optimization technique. The optimum

Table 1: Formulation variables and their levels for CCD

\begin{tabular}{llll}
\hline Batch code & $X 1$ & $X 2$ & $X 3$ \\
\hline RT 1 & -1 & -1 & -1 \\
RT 2 & 1 & -1 & -1 \\
RT 3 & -1 & 1 & -1 \\
RT 4 & 1 & 1 & -1 \\
RT 5 & -1 & -1 & 1 \\
RT 6 & 1 & -1 & 1 \\
RT 7 & 1 & 1 & 1 \\
RT 8 & 1 & 1 & 1 \\
RT 9 & -1.68 & 0 & 0 \\
RT 10 & 1.68 & 0 & 0 \\
RT 11 & 0 & -1.68 & 0 \\
RT 12 & 0 & 1.68 & 0 \\
RT 13 & 0 & 0 & -1.68 \\
RT 14 & 0 & 0 & 1.68 \\
RT 15 & 0 & 0 & 0 \\
RT 16 & 0 & 0 & 0 \\
RT 17 & 0 & 0 & 0 \\
\hline
\end{tabular}

batch exhibited desired in vitro adhesion parameters, like peel, tack, shear, and permeation rate, which is suitable for 3 days' wear properties and desired permeation rate. The optimum batches were tested for appearance, weight of matrix, thickness, \% assay of drug content, in vitro adhesion testing, cold flow study, and ex vivo skin permeation studies, and stability study.

\section{Materials AND Methods}

\section{Materials}

Rotigotine was obtained as gratis from Zydus Cadila, Ahmedabad, India. PSA: Bio PSA 4302 and Bio PSA 4202 were obtained as a gift sample from Dow Chemicals. PSA: Durotak 87-2054 and Durotak 6908 were obtained as a gift sample from Henkel (Drogenbos, Belgium). Human cadaver skin samples were obtained from Science Care Inc. (Philadelphia, USA). Propylene glycol, ascorbyl palmitate, and $\alpha$-tocopherol were supplied by Finar Chemical Corporation Pvt. Ltd. (Ahmedabad, India). Povidone K29/32 was received from ISP Technologies. Scotchpak 9730, Cotran 9720, Scotchpak 9757, and Scotchpak 1109 were obtained from 3M India Limited (Mumbai, India). Fluoropolymer coated release liner Scotchpak 1022 was received as gift samples from 3M India Limited (Mumbai, India). PET film XL was supplied by Kaygee-Loparex India Pvt. Ltd. (Gujarat, India). Other analytical grade chemicals, solvents, and reagents were used.

\section{Fabrication of Rotigotine Drug in Adhesive Patches (Dot-Matrix Technology)}

The required quantity of ascorbyl palmitate and $\alpha$-tocopherol were dissolved in ethyl acetate and dehydrated alcohol. Ascorbyl palmitate and $\alpha$-tocopherol were used as antioxidant in formulation. Povidone K29/32 was added slowly under stirring. Mix for 10 minutes under $200 \mathrm{rpm}$. Precisely weighed rotigotine was added and dissolved under mixing. Durotak 2054 (acrylate adhesive) was added slowly and mix it for 10 minutes under stirring $200 \mathrm{rpm}$. Bio-PSA 4302 (silicone adhesive) was added under mixing to get a uniform mixture. Permeation enhancer (propylene glycol) was added and mixed for 10 minutes. All formulations were kept at ambient room temperature for 24 hours to achieve equilibrium. Blend was coated on fluoropolymer coated surface of release liner with uniform thickness to achieve 100 dry GSM in Mathis-I lab coater for 20 minutes at $80^{\circ} \mathrm{C}$. Dried sheets were laminated with backing film using Benchtop laminator (LL-100-A, Cheminstruments). Prepared laminates were die cut using $10 \mathrm{~cm}^{2}$ die. Die-cut patches were pouched in paper pouches and stored at controlled room temperature till further evaluation. A total of 17 formulations were made with different concentrations of silicone adhesive (Bio-PSA4302), povidone K29/32, and propylene glycol, as given in Table 1. For all the formulation, the concentration of ascorbyl palmitate and $\alpha$-tocopherol were kept 0.02 and 
0.09, respectively. Durotak 2054 were added 1:9 ratio to required concentration of silicone adhesive. Rotigotine concentration in all formulations was 9\%. Schematic diagram for fabrication of rotigotine TDS is given in Fig. 1.

\section{Experimental Design}

A CCD was selected in the optimization of the formulation. In the present investigation, silicone adhesive concentration (X1), povidone K29/32 concentration (X2), and propylene glycol concentration (X3) were selected as independent variables. The peel $(\mathrm{g} / \mathrm{mm})$, tack $\left(\mathrm{g} / \mathrm{mm}^{2}\right)$, shear (minutes), and flux $\left(\mu \mathrm{g} / \mathrm{cm}^{2} / \mathrm{hr}\right)$ were selected as dependent variables to define design space. The experimental design with corresponding compositions is outlined in Tables 1 and 2. Experiment sequence was generated and randomized using Design Expert ${ }^{\circledR}$ ver. 12 (Stat-Ease Inc., Minneapolis, MN 55413) software to avoid any bias. A total of 17 experiments were designed by the

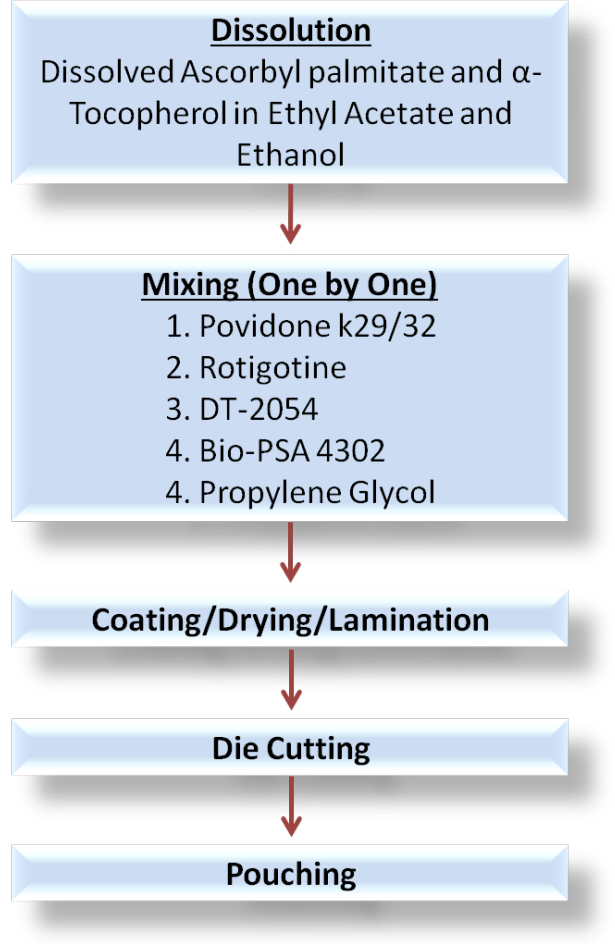

Fig. 1: Schematic diagram for fabrication of rotigotine TDS

Table 2: Translation of coded levels into actual values of independent variables

\begin{tabular}{llll}
\hline & \multicolumn{2}{l}{ Actual values } & \\
\cline { 2 - 4 } $\begin{array}{l}\text { Coded } \\
\text { levels }\end{array}$ & $\begin{array}{l}\text { Silicone adhesive } \\
\text { concentration } \\
(X 1)\end{array}$ & $\begin{array}{l}\text { Povidone K29/32 } \\
\text { concentration } \\
(X 2)\end{array}$ & $\begin{array}{l}\text { Propylene glycol } \\
\text { concentration } \\
(X 3)\end{array}$ \\
\hline-1 & $70 \%$ & $1 \%$ & $2 \%$ \\
0 & $80 \%$ & $3 \%$ & $4.5 \%$ \\
1 & $90 \%$ & $5 \%$ & $7 \%$ \\
-1.68 & 63.18 & $0(-0.36)$ & 0.29 \\
1.68 & 96.82 & 6.36 & 8.7 \\
\hline
\end{tabular}

software with 3 center points. Table 3 lists the studied responses and their constraints.

\section{Statistical Analysis}

The statistical analysis of CCD design batches was performed by Design Expert ${ }^{\circledR}$ ver. 12 (Stat-Ease Inc., Minneapolis, MN 55413) software. All statistical analyses regarding DoE batches were performed using the same software. Response surface plots and overlaid contour plots were generated using the same software.

\section{Evaluation of Rotigotine Transdermal Patches}

\section{Preformulation Studies}

Solubility studies were carried out by preparing a saturated solution of drug in different permeation enhancers and solvents. In the drug-excipient compatibility study, the drug was mixed with various excipients in 1:1 ratio. This mixture was kept in glass vials then properly capped and sealed with teflon tape. Two vials of each mixture were put at controlled room temperature $\left(25^{\circ} \mathrm{C}\right)$ and in the hot air oven at $40^{\circ} \mathrm{C}$ for one month period. Transmission study was done in order to check the permeability of the drug through backing film and liner. This study is critical in the selection of the backing film and release liner. If the drug is permeable through any of these, it may cause formulation error, and drug content in final formulation may decrease as some drug may leach or transmit through backing or liner during the formulation. A saturated solution of rotigotine was prepared in propylene glycol. Several pieces of backing film/ release liners were cut of $12.56 \mathrm{~cm}^{2}$ size and applied on Franz diffusion cell. The donor cell was then mounted on above it, and the two cells were clamped tightly so that the backing film/ release liners mounted on the receptor was sandwiched between the donor and the receptor cells. The receptor cell of the diffusion cell apparatus was filled with phosphatebuffered saline pH 7.4. $2 \mathrm{~mL}$ of a saturated solution of rotigotine was filled in the donor compartment using a syringe. A magnetic stirrer was used to keep the receptor media under stirring. The temperature was maintained at $40^{\circ} \mathrm{C}$. The receptor phase was sampled at initial, 24,48 , 96,120 , and 168 hours, and the withdrawn samples were analyzed for rotigotine content. Uptake study was done in order to check the percent drug uptake or absorbed by backing and release liner. For uptake study, a saturated solution of rotigotine was prepared in propylene glycol. Several $1 \mathrm{~cm}^{2}$ pieces of backing films/ release liners

Table 3: Studied responses and their constraints

\begin{tabular}{ll}
\hline Responses (dependent variables) & Constraints (goal) \\
\hline Peel $(\mathrm{g} / \mathrm{mm})$ & $>20$ \\
Tack $\left(\mathrm{g} / \mathrm{mm}^{2}\right)$ & $>10$ \\
Shear $($ minutes $)$ & $>80$ \\
Flux $\left(\mu \mathrm{g} / \mathrm{cm}^{2} / \mathrm{hr}\right)$ & $>8.1$ \\
\hline
\end{tabular}


were cut and immersed in rotigotine-propylene glycol solution, and stored at $40^{\circ} \mathrm{C} / 75 \%$ relative humidity (RH) and $25^{\circ} \mathrm{C} / 60 \% \mathrm{RH}$. The backing film/ release liner was sampled at the interval of 2,4 , and 6 weeks. The sample was wiped carefully and analyzed for rotigotine content. For crystallization study, patches were prepared with different concentrations of rotigotine, and stored at different stability conditions as follows: freeze-thaw cycle, accelerated stability, 90\% RH, and controlled room temperature for 60 days.

The final transdermal patches were evaluated for appearance, the weight of matrix, thickness, \% assay of drug, in vitro adhesion testing, cold flow study, and ex vivo skin permeation studies.

\section{Appearance}

Prepared TDSs were inspected for appearance visually.

\section{Matrix Weight Variation}

The total weight of each patch was taken individually, and the weight of the matrix was calculated by removing the tare weight of release liner, backing film, and mean value calculated. ${ }^{[14]}$

\section{Thickness of Patch}

The thickness of the patch was measured using a micrometer at five different places of patch, and mean values were calculated. ${ }^{[15]}$

\section{Rotigotine Content by High-Performance Chromatography (HPLC)}

The reverse-phase HPLC method was used for the determination of rotigotine in presence of its degradation products. The analysis of samples was carried out using hypersil BDS C18 column. The mobile phase comprised of $0.01 \mathrm{~N}$ potassium dihydrogen orthophosphate (adjusted to $\mathrm{pH} 4.8$ with OPA solution), acetonitrile $(45: 55 \mathrm{v} / \mathrm{v})$ at a flow rate of $1 \mathrm{~mL} / \mathrm{min}$. The flow rate was maintained at $0.4 \mathrm{~mL} / \mathrm{min}$, and detection wavelength was $225 \mathrm{~nm}$, using PDA detector. ${ }^{[16]}$

\section{In vitro Adhesion Testing (Peel, Tack, and Shear)}

In vitro adhesion property of patch is characterized by peel strength (minimal force which takes to remove the patch from its surface), shear strength (the patch applies a resistance against the flow/ detachment) and tack strength (the property of the patch to form bond with the contact surface under light pressure and brief contact). ${ }^{[17-19]}$ Tack is the early physical bonding of patch onto the skin normally occurs in few seconds. Peel strength of patch was measured using LLOYD instrument. The test patch is attached to the steel plate after removing release liner. The patch should be adhered to the steel plate in such a way that about a 1-inch portion of the patch should not adhere to the plate. Now, roll the roller on it for two-three times. Allow it to stand for 1-minute. Fix the steel plate on instrument and attach the 1-inch portion on the upper jaw. Peel at $180^{\circ}$ using crosshead speed $-300 \mathrm{~mm} / \mathrm{min}$ and load cell-50 Newton. Report the average peel adhesion of five measurements in $\mathrm{g} / \mathrm{mm}$ using the width of TDS. Tack was measured using Lloyd (AMETEK) instrument. One patch was taken and cut it to size of 1-inch square. Release liner was removed and applied on test panel such way that the adhesion side remain upward direction towards hole. Machine was started at a speed of $610 \mathrm{~mm} / \mathrm{min}$ to bring contact of probe to adhesive side of patch. After 1-second contact time, removed probe from adhesive at the same speed. Note down force (maximum) required for removing the probe from patch. Shear was measured using Chem. Instrument (10 bank shear tester). Patch was cut of 0.5 -inches width. Patch was adhered on to the stainless steel plate up to 0.5 -inches mark portion of release liner. Roll the roller on it, and allow it to stand for 15 minutes. The other end was attached with hook, and after completion of required dwell time, 100 grams weight was hanged on the hook. The time required to fall down the patch was measured.

\section{Cold Flow Study of Rotigotine Patch}

Cold flow is the movement of adhesive outside the borders of TDS during storage. Cold flow was measured by microscopical method by viewing the patch under microscope at initial and after 1-month, when stored at $40^{\circ} \mathrm{C} / 75 \%$ RH. $^{[20-22]}$

\section{Ex vivo Permeation Study of Rotigotine Patch}

Hairless human cadaver skin is used for permeation studies. Dermatomed of human cadaver skin was received from vendor. Dermatomed of human cadaver skin was dipped in hot water for 2 to 3 hours at $55 \pm 5^{\circ} \mathrm{C}$. After 2 to 3 hours, human cadaver skin was removed from hot water, and stratum corneum of skin was separate from dermatomed skin using a cotton swab. Separated stratum corneum was dried overnight at controlled room temperature. After drying of the excised stratum corneum, it was stored at 2 to $8^{\circ} \mathrm{C}$ till further used. The ex vivo permeation study was performed using modified Franz diffusion cell on excised stratum corneum of skin. The excised stratum corneum was cut into size of $2 \mathrm{~cm}^{2}$, using die cutter, and placed between the receptor and donor compartments so that the dermal side of the skin faced the receiver fluid. The release liner was removed from the patch (patch size: $10 \mathrm{~cm}^{2}$ and API per patch was $9 \mathrm{mg}$ ) and applied on the excised stratum corneum. Specified volume of diffusion medium (phosphate buffer with pH 7.4) was filled into the Franz diffusion cell. Franz diffusion cell was placed on magnetic stirrer, and a small magnetic bead was added and stirred the content under $500 \mathrm{rpm}$ to keep them well mixed. The aliquots of diffusion medium were removed at specified sampling points and filtered through Whatman ${ }^{\circledR}$ filter grade 41 . Amount of drug was determined by HPLC using appropriated method, as discussed. Same volume of fresh diffusion medium after 
each removal was reinstated into the diffusion cell to maintain sink condition. The study was continued up to 72 hours. Each study was carried out on three skin $(n=3)$, and mean flux was calculated. ${ }^{[23-25]}$

\section{Stability Study}

The optimized formulation of rotigotine TDS was pouched in paper pouch (41 GSM paper/ 17 GSM low density polyethylene (LDPE)/ $9 \mu \mathrm{Al} / 35$ GSM LDPE), and kept at $25^{\circ} \mathrm{C} / 65 \% \mathrm{RH}$ and $40^{\circ} \mathrm{C} / 75 \% \mathrm{RH}$, for 3 months. Various stability tests, like appearance, assay, related substances, in vitro adhesion, and cold flow of patches were performed at different time points.

\section{RESULTS}

\section{Effect of Factors on the Responses}

Effect of silicone adhesive concentration (X1), povidone K29/32 concentration (X2), and propylene glycol concentration (X3) on various measured responses was summarised in Table 4.

\section{In vitro Adhesion Testing (Peel, Tack, and Shear)}

Results of in vitro adhesion testing (peel, tack, and shear) are mentioned in Table 4. ANOVA results and regression coefficients of measured responses are given in Tables 5 and 6.

Response 1: Peel

The peeling-off plays a crucial role as the higher the peel adhesion, the more painful the removal. Peel resistance should not be assumed as an expression of the strength of the adhesive bond because this parameter does not necessarily relate to the intrinsic adhesiveness. The detachment is a complex process that involves the extension and bending of the patch matrix, and the backing layer prior to the separation. The impact of silicone adhesive concentration, povidone K29/32 concentration, and propylene glycol concentration on peel strength was studied, and the obtained responses were given in Table 4. The quadratic model with $\mathrm{F}$ value of 3.87 implies that the model was significant. The model $p$ value was 0.0441 indicated that the model terms were significant. $\mathrm{p}$ values for silicone adhesive concentration was 0.0219 , for povidone K29/32 concentration was 0.0437 , and for propylene glycol concentration was 0.0764 . The regression coefficient value $R^{2}$ value was 0.8326 , and adjusted $R^{2}$ value was 0.6173 indicated that there were minimum variations in the experimental model. The polynomial equation in terms of coded factors was used to make predictions about the peel value of patch for given levels of each factor.

$$
\begin{gathered}
\text { Peel }=+29.30+3.86 \times \mathrm{X} 1-3.24 \times \mathrm{X} 2-2.74 \times \mathrm{X} 3- \\
0.5500 \mathrm{X} 1 \mathrm{X} 2+0.2000 \mathrm{X} 1 \mathrm{X} 3+2.25 \mathrm{X} 2 \mathrm{X} 3-4.09 \mathrm{X}^{2}+ \\
0.8613 \mathrm{X}^{2}-3.38 \mathrm{X3}^{2}
\end{gathered}
$$

From the $\mathrm{p}$ values, two linear coefficients term $\mathrm{X} 1$, term $\mathrm{X} 2$, and one quadratic coefficient $\mathrm{X} 1^{2}$ were significant. The effects of factors on peel strength were presented in the

\begin{tabular}{|c|c|c|c|c|c|c|c|}
\hline \multirow[b]{2}{*}{ Batch code\# } & \multirow[b]{2}{*}{$X 1$} & \multirow[b]{2}{*}{$X 2$} & \multirow[b]{2}{*}{ X3 } & \multirow{2}{*}{$\begin{array}{l}\text { Peel } \\
(\mathrm{g} / \mathrm{mm})\end{array}$} & \multirow{2}{*}{$\begin{array}{l}\text { Tack } \\
\left(\mathrm{g} / \mathrm{mm}^{2}\right)\end{array}$} & \multirow{2}{*}{$\begin{array}{l}\text { Shear } \\
\text { (minutes) }\end{array}$} & \multirow{2}{*}{$\begin{array}{l}\text { Flux } \\
\left(\mu g / \mathrm{cm}^{2} / \mathrm{hr}\right)\end{array}$} \\
\hline & & & & & & & \\
\hline RT 1 & -1 & -1 & -1 & 29.8 & 8 & 105 & 6.3 \\
\hline RT 2 & 1 & -1 & -1 & 34.2 & 15 & 110 & 6.1 \\
\hline RT 3 & -1 & 1 & -1 & 21 & 9 & 110 & 7.1 \\
\hline RT 4 & 1 & 1 & -1 & 22 & 11 & 120 & 6.5 \\
\hline RT 5 & -1 & -1 & 1 & 17 & 21 & 60 & 9.2 \\
\hline RT 6 & 1 & -1 & 1 & 21 & 25 & 80 & 8.7 \\
\hline RT 7 & 1 & 1 & 1 & 16 & 15 & 100 & 10.1 \\
\hline RT 8 & 1 & 1 & 1 & 19 & 23 & 110 & 9.2 \\
\hline RT 9 & -1.68 & 0 & 0 & 6 & 14 & 85 & 9.5 \\
\hline RT 10 & 1.68 & 0 & 0 & 30 & 23 & 105 & 8.5 \\
\hline RT 11 & 0 & -1.68 & 0 & 38 & 21 & 75 & 7.5 \\
\hline RT 12 & 0 & 1.68 & 0 & 26 & 13 & 105 & 8.9 \\
\hline RT 13 & 0 & 0 & -1.68 & 21 & 5 & 98 & 4.5 \\
\hline RT 14 & 0 & 0 & 1.68 & 19 & 19 & 70 & 10.1 \\
\hline RT 15 & 0 & 0 & 0 & 32.5 & 14 & 105 & 8.2 \\
\hline RT 16 & 0 & 0 & 0 & 27.5 & 15 & 95 & 8 \\
\hline RT 17 & 0 & 0 & 0 & 27.8 & 14 & 100 & 8.1 \\
\hline
\end{tabular}
form of response surface plots in Fig. 2.

Table 4: Matrix of experiments of CCD and measured responses

X1: Silicone adhesive concentration; X2: Povidone K29/32 concentration; X3: Propylene glycol concentration 
Shailesh T. Prajapati et al.

Table 5: ANNOVA summary output showing effect of independent factors on measured responses

\begin{tabular}{|c|c|c|c|c|c|}
\hline \multicolumn{2}{|l|}{ Source } & \multirow[t]{2}{*}{$\begin{array}{l}\text { Sum of } \\
\text { squares }\end{array}$} & \multirow[t]{2}{*}{$D f$} & \multirow[t]{2}{*}{$\begin{array}{l}\text { Mean } \\
\text { square }\end{array}$} & \multirow{2}{*}{$\begin{array}{l}\text { F value } \\
\text { ANOVA re }\end{array}$} \\
\hline & & & & & \\
\hline \multicolumn{2}{|c|}{ Quadratic model } & 824.74 & 9 & 91.64 & 3.87 \\
\hline \multicolumn{2}{|l|}{$\mathrm{X} 1$} & 203.85 & 1 & 203.85 & 8.6 \\
\hline \multicolumn{2}{|l|}{$\mathrm{X} 2$} & 142.93 & 1 & 142.93 & 6.03 \\
\hline \multicolumn{2}{|l|}{ X3 } & 102.22 & 1 & 102.22 & 4.31 \\
\hline \multicolumn{2}{|l|}{ Residual } & 165.88 & 7 & 23.7 & - \\
\hline \multirow{2}{*}{\multicolumn{2}{|c|}{ Lack of fit }} & 150.15 & 5 & 30.03 & 3.82 \\
\hline & & & & & ANOVA res \\
\hline \multicolumn{2}{|c|}{ Quadratic model } & 500.9 & 9 & 55.66 & 22.63 \\
\hline \multicolumn{2}{|l|}{$\mathrm{X} 1$} & 95.62 & 1 & 95.62 & 38.88 \\
\hline \multicolumn{2}{|l|}{$\mathrm{X} 2$} & 43.79 & 1 & 43.79 & 17.8 \\
\hline \multicolumn{2}{|l|}{ X3 } & 305.05 & 1 & 305.05 & 124.03 \\
\hline \multicolumn{2}{|l|}{ Residual } & 17.22 & 7 & 2.46 & - \\
\hline \multirow{2}{*}{\multicolumn{2}{|c|}{ Lack of fit }} & 16.55 & 5 & 3.31 & 9.93 \\
\hline & & & & & ANOVA res \\
\hline \multicolumn{2}{|c|}{ Quadratic model } & $3,844.58$ & 9 & 427.18 & 6.36 \\
\hline \multicolumn{2}{|l|}{$\mathrm{X} 1$} & 452.78 & 1 & 452.78 & 6.74 \\
\hline \multicolumn{2}{|l|}{$\mathrm{X} 2$} & $1,343.48$ & 1 & $1,343.48$ & 19.99 \\
\hline \multicolumn{2}{|l|}{$\mathrm{X} 3$} & $1,478.35$ & 1 & $1,478.35$ & 22 \\
\hline \multicolumn{2}{|l|}{ Residual } & 470.36 & 7 & 67.19 & - \\
\hline \multirow{2}{*}{\multicolumn{2}{|c|}{ Lack of fit }} & 420.36 & 5 & 84.07 & 3.36 \\
\hline & & & & & ANOVA re \\
\hline \multicolumn{2}{|c|}{ Quadratic model } & 37.08 & 9 & 4.12 & 55.96 \\
\hline \multicolumn{2}{|l|}{$\mathrm{X} 1$} & 1.1 & 1 & 1.1 & 14.99 \\
\hline \multicolumn{2}{|l|}{$\mathrm{X} 2$} & 1.8 & 1 & 1.8 & 24.42 \\
\hline X3 & & 31.13 & 1 & 31.13 & 422.82 \\
\hline Residual & & 0.5153 & 7 & 0.0736 & - \\
\hline & Table 6: & ression coe & ents & summary & \\
\hline Factors & Peel & Tack & She & & Flux \\
\hline Intercept & 29.3 & 14.34 & 99. & & 8.12 \\
\hline $\mathrm{X} 1$ & 3.86 & 2.65 & 5.7 & & -0.2842 \\
\hline $\mathrm{X} 2$ & -3.24 & -1.79 & 9.9 & & 0.3628 \\
\hline X3 & -2.74 & 4.73 & -10 & & 1.51 \\
\hline $\mathrm{X} 1 \mathrm{X} 2$ & -0.55 & -0.125 & -0.6 & & -0.1 \\
\hline X1X3 & 0.2 & 0.375 & 1.8 & & -0.075 \\
\hline $\mathrm{X} 2 \mathrm{X} 3$ & 2.25 & -0.625 & 6.8 & & 0.025 \\
\hline $\mathrm{X} 1^{2}$ & -4.09 & 1.46 & 0.5 & 67 & 0.2581 \\
\hline $\mathrm{X} 2^{2}$ & 0.8613 & 0.9319 & -1.2 & & -0.0247 \\
\hline$X 3^{2}$ & -3.38 & -0.8359 & -3.3 & & -0.3429 \\
\hline
\end{tabular}

Response 2: Tack

The impact of silicone adhesive concentration, povidone K29/32 concentration, and propylene glycol concentration on tack was studied, and the obtained responses were $p$ value Adjusted Predicted Adequate $\begin{array}{llllll}\text { prob }>F & \text { Press } & R^{2} & R^{2} & R^{2} & \text { precision }\end{array}$

sults for peel

$\begin{array}{llllll}0.0441 & 1,177.91 & 0.8326 & 0.6173 & -0.1891 & 6.9474\end{array}$

0.0219

0.0437

0.0764

0.2204

ults for tack

$\begin{array}{llllll}0.0002 & 143.24 & 0.9668 & 0.9241 & 0.7235 & 18.4227\end{array}$

0.0004

0.0039

$<0.0001$

0.094

sults for shear

$\begin{array}{llllll}0.0117 & 3,332.14 & 0.891 & 0.7508 & 0.2278 & 8.3829\end{array}$

0.0356

0.0029

0.0022

0.2449

$-\quad-\quad-$

ts for flux

$\begin{array}{llllll}<0.0001 & 3.8 & 0.9863 & 0.9687 & 0.899 & 27.6609\end{array}$

0.0061

0.0017

$<0.0001$
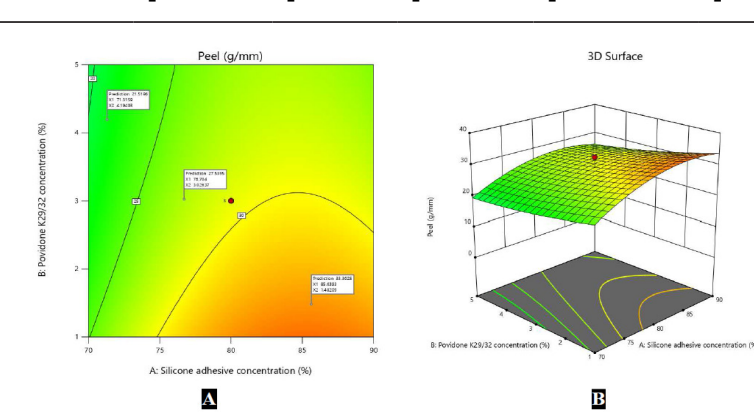

Fig. 2: A) Contour plot of peel strength; B) 3D surface plot of peel strength

given in Table 4. The quadratic model with $\mathrm{F}$ value of 22.63 implies that the model was significant. The model $p$ value was 0.0002 indicated that the model terms were significant. p values for silicone adhesive concentration was 0.0004 , for povidone K29/32 concentration was 0.0039 , and for propylene glycol concentration was $<0.0001$. The regression coefficient value $\mathrm{R}^{2}$ value was 0.9668 , and adjusted $\mathrm{R}^{2}$ value was 0.9241 ; indicated that there 
was minimum variations in the experimental model. The polynomial equation in terms of coded factors was used to make predictions about tack value of patch for given levels of each factor.

Tack $=+14.34+2.65 \times \mathrm{X} 1-1.79 \times \mathrm{X} 2+4.73 \times \mathrm{X} 3-$ $0.1250 \mathrm{X} 1 \mathrm{X} 2+0.3750 \mathrm{X} 1 \mathrm{X} 3-0.6250 \mathrm{X} 2 \mathrm{X} 3+1.46 \mathrm{X}^{2}+$ $0.9319 \times 2^{2}-0.8359 \mathrm{X3}^{2}$

From the $\mathrm{p}$ values, three linear coefficients term X1, term $\mathrm{X} 2$, and term $\mathrm{X} 3$, and one quadratic coefficient $\mathrm{X} 1^{2}$ were significant. The effects of factors on tack strength were presented in the form of response surface plots in Figs 3 and 4.

\section{Response 3: Shear}

The impact of silicone adhesive concentration, povidone K29/32 concentration, and propylene glycol concentration on shear was studied, and the obtained responses were given in Table 4 . The quadratic model with $\mathrm{F}$ value of 6.36 implies that the model was significant. The model $p$ value was 0.0117 indicated that the model terms were significant. $\mathrm{p}$ values for silicone adhesive concentration were 0.0356 , for povidone $\mathrm{K} 29 / 32$ concentration was 0.0029 , and for propylene glycol concentration was 0.0022 . The polynomial equation in terms of coded factors was used to make predictions about the shear value of patch for given levels of each factor.

Shear $=+99.33+5.76 \times \mathrm{X} 1+9.92 \times \mathrm{X} 2-10.4 \times \mathrm{X} 3-$ $0.625 \mathrm{X} 1 \mathrm{X} 2+1.87 \mathrm{X} 1 \mathrm{X} 3+6.87 \mathrm{X} 2 \mathrm{X} 3+0.5267 \mathrm{X}^{2}-1.24$

$$
\mathrm{X} 2^{2}-3.36 \mathrm{X}^{2}
$$

From the $\mathrm{p}$ values three linear coefficients term X1, term X2, and term X3 were significant. The effects of factors on shear strength were presented in the form of response surface plots in Figs 5 and 6.

\section{Ex vivo Permeation Study (Flux)}

Results of ex vivo permeation study are mentioned in Table 4. ANOVA results and regression coefficients of flux
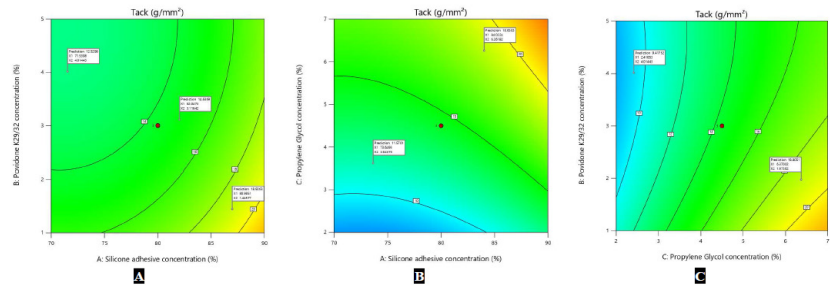

Fig. 3: Contour plot of tack; A) X1 and X2; B) X1 and X3; C) $\mathrm{X} 3$ and $\mathrm{X} 2$
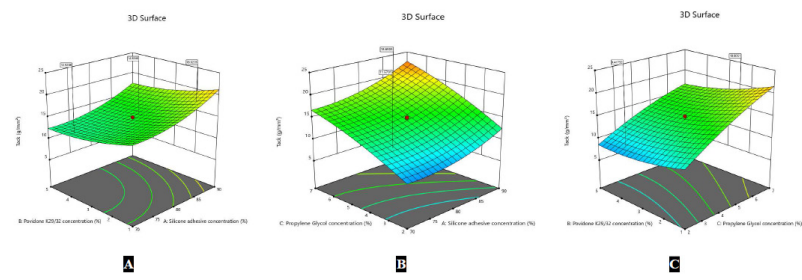

Fig. 4: 3D surface plot of tack; A) X1 and X2; B) X1 and X3; C) $\mathrm{X} 3$ and $\mathrm{X} 2$ are given in Tables 5 and 6.

\section{Response 4: Flux (Permeation Rate)}

The impact of silicone adhesive concentration, povidone K29/32 concentration, and propylene glycol concentration on permeation rate was studied, and the obtained responses were given in Table 4 . The quadratic model with $F$ value of 55.96 implies that the model was significant. The model $p$ value was $<0.0001$ indicated that the model terms were significant. p values for silicone adhesive concentration was 0.0061 , for povidone K29/32 concentration was 0.0017 , and for propylene glycol concentration was $<0.0001$. The regression coefficient value $R^{2}$ value was 0.9863 , and adjusted $R^{2}$ value was 0.9687; indicated that there was minimum variations in the experimental model. The polynomial equation in terms of coded factors was used to make predictions about permeation rate of patch for given levels of each factor.

Flux $=+8.12-0.2842 \times \mathrm{X} 1+0.3628 \times \mathrm{X} 2+1.51 \times$ $\mathrm{X} 3-0.1 \mathrm{X} 1 \mathrm{X} 2-0.075 \mathrm{X} 1 \mathrm{X} 3+0.025 \mathrm{X} 2 \mathrm{X} 3+0.2581 \mathrm{X}^{2}-$

$$
0.0247 \times 2^{2}-0.3429 \times 3^{2}
$$

From the $\mathrm{p}$ values, three linear coefficients terms X1, $\mathrm{X} 2$, and $\mathrm{X} 3$, and two quadratic coefficients $\mathrm{A}^{2}$ and $\mathrm{C}^{2}$ were significant. The effects of factors on permeation rate were presented in the form of response surface plots in Figs 7 and 8.

\section{Graphical Optimization of Measured Responses (Overlay Plot)}

Design Expert ${ }^{\oplus}$ ver. 12 (Stat-Ease Inc., Minneapolis, MN 55413) has in-built option for graphical optimization, which frames "design-space" based on given constraints for measured responses. Based on available data for in vitro adhesion testing and ex vivo permeation studies, "overlay plot," as shown in Fig. 9, was obtained through graphical optimization. Design space is shown in yellow color. Independent factors with levels selected
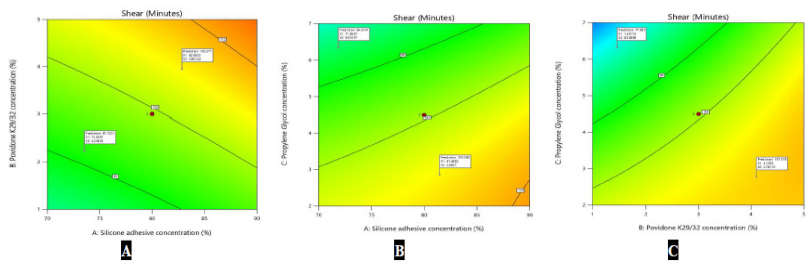

Fig. 5: Contour plot of shear; A) X1 and X2; B) X1 and X3; C) $\mathrm{X} 3$ and $\mathrm{X} 2$
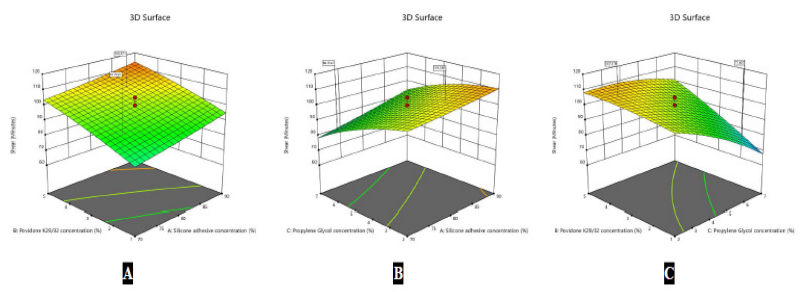

Fig. 6: 3D surface plot of shear; A) X1 and X2; B) X1 and X3; C) $\mathrm{X} 3$ and $\mathrm{X} 2$ 

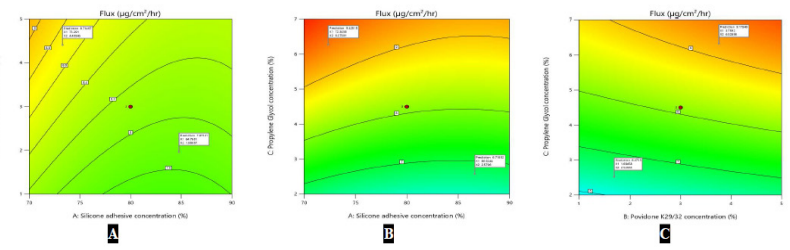

Fig. 7: Contour plot of flux; A) X1 and X2; B) X1 and X3; C) $X 3$ and $X 2$
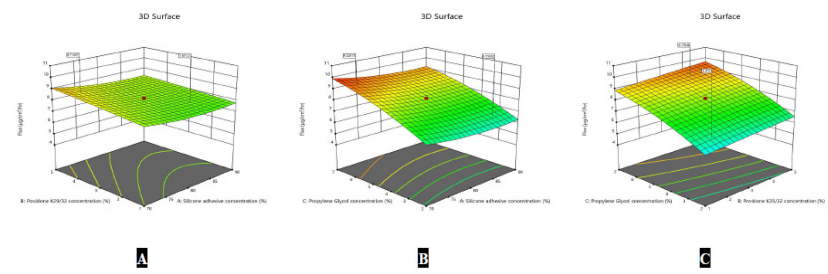

Fig. 8: 3D surface plot of flux; A) $X 1$ and $X 2$; B) $X 1$ and $X 3$; C) $X 3$ and $X 2$
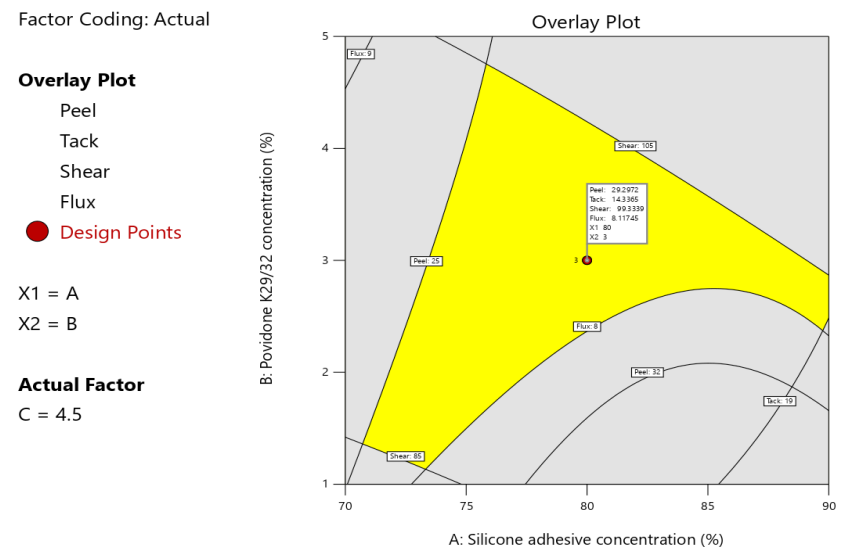

Fig. 9: Overlay plot showing design space for rotigotine TDS

within design-space yield desired results within given specifications. From the data, batches RT 15, RT 16, and RT 17 (80\% silicone adhesive concentration, 3\% povidone concentration, and $4.5 \%$ propylene glycol concentration) were found to be optimum batches.

\section{Checkpoint Batches and Cross-Validation of DoE Model}

Two experiments were performed at different concentrations of silicon adhesive, povidone, and propylene glycol to check reliability of the model at values other than those used in experimental design. The experimental values and predicted values for each response were shown in Table 7. Bias or \% relative error was calculated for each response, as per the following equation ${ }^{[26,27]}$ :

$$
\% \text { bias }=\left[\frac{\text { Predicted value }- \text { Experimental value }}{\text { Predicted value }} \times 100 \%\right]
$$

From the data, it can be deduced that the equations satisfactorily demonstrate influence of formulation variables on the responses of the study due to fairly good agreement between the predicted and experimental values in both checkpoint batches.

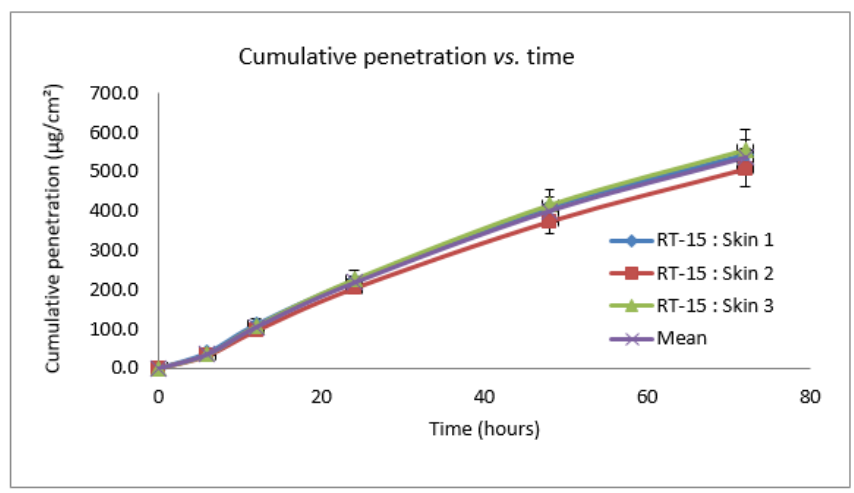

Fig. 10: Cumulative penetration of optimum batch (RT 15) on three different skins

\section{Characterization of Optimum Formulation (RT 15) of Rotigotine TDS}

\section{Appearance}

Patches of optimum formulation were rounded squareshaped transparent release liner with tan-colored backing film. Upon removal of the transparent release liner, a uniform matrix layer on the backing is visible and substantially free of external particulate matter and bubbles.

\section{Weight of Matrix Uniformity}

The weight of matrix of all patches is uniform. The average matrix weight of patches was found at $101.15 \pm 1.13 \mathrm{mg}$ of $10 \mathrm{~cm}^{2}$ (dry 100 GSM).

\section{Thickness of Patch}

The thickness of patch ensured uniformity of coating/ drying and lamination process. The average thickness of patches was found $223.08 \pm 2.29 \mu \mathrm{m}$, including backing film and release liner (dry 100 GSM).

\section{Rotigotine Content by HPLC}

The assay value ranges from $100.6 \pm 1.1 \%$.

In vitro Adhesion Testing (Peel, Tack, and Shear)

In vitro adhesion testing of optimum batch was performed. The average peel, tack, and shear values of patches were found $32.5 \pm 1.07 \mathrm{~g} / \mathrm{mm}, 14 \pm 0.89 \mathrm{~g} / \mathrm{mm}^{2}$, and $105 \pm 2.61$ minutes, respectively.

\section{Cold Flow Study of Optimum Batch}

The cold flow in optimum batch was found $3.5 \pm 0.4 \%$ after 1-month, when stored at $40^{\circ} \mathrm{C} / 75 \% \mathrm{RH}$.

\section{Ex vivo Permeation Study of Rotigotine Patch}

Flux study was performed on three different skins. Mean cumulative penetration amount and mean flux of optimum batch was found $535.25 \pm 25.47 \mu \mathrm{g} / \mathrm{cm}^{2}$ and $8.1 \pm 0.51 \mu \mathrm{g} / \mathrm{cm}^{2} / \mathrm{hr}$, respectively, as per given Figs 10 and 11 . 
Formulation Development of Rotigotine TDS

Table 7: Comparison between experimental and predicted responses for checkpoint batches

\begin{tabular}{|c|c|c|c|c|c|c|c|}
\hline \multirow[b]{2}{*}{ Responses } & \multirow[b]{2}{*}{$\begin{array}{l}\text { Checkpoint } \\
\text { batch }\end{array}$} & \multicolumn{3}{|c|}{ Factors } & \multirow{2}{*}{$\begin{array}{l}\text { Experimental } \\
\text { (observed) } \\
\text { values }\end{array}$} & \multirow[b]{2}{*}{$\begin{array}{l}\text { Predicted } \\
\text { values }\end{array}$} & \multirow[b]{2}{*}{ Bias (\%) } \\
\hline & & $\begin{array}{l}\text { X1: Silicone adhesive } \\
\text { concentration }\end{array}$ & $\begin{array}{l}\text { X2: Povidone } \\
\text { concentration }\end{array}$ & $\begin{array}{l}\text { X3: Propylene glycol } \\
\text { concentration }\end{array}$ & & & \\
\hline \multirow{2}{*}{ R1: Peel } & 1 & 87.32 & 1.97 & 4.7 & 33.1 & 31.71 & -4.39 \\
\hline & 2 & 78.87 & 2.35 & 4.72 & 28.7 & 29.59 & 2.99 \\
\hline \multirow{2}{*}{ R1: Tack } & 1 & 87.32 & 1.97 & 4.7 & 17 & 18.69 & 9.02 \\
\hline & 2 & 78.87 & 2.35 & 4.72 & 14 & 15.15 & 7.62 \\
\hline \multirow{2}{*}{ R1: Shear } & 1 & 87.32 & 1.97 & 4.7 & 95 & 97.63 & 2.69 \\
\hline & 2 & 78.87 & 2.35 & 4.72 & 100 & 94.16 & -6.2 \\
\hline \multirow{2}{*}{ R1: Flux } & 1 & 87.32 & 1.97 & 4.7 & 8.1 & 8.16 & 0.75 \\
\hline & 2 & 78.87 & 2.35 & 4.72 & 7.9 & 8 & 1.31 \\
\hline
\end{tabular}

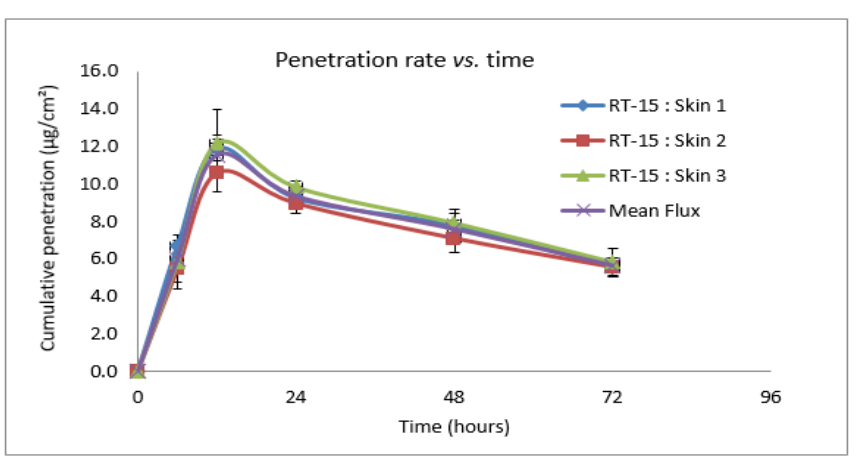

Fig. 11: Penetration rate (flux rate) of optimum batch (RT 15) on three different skins

\section{Stability Study}

Stability study of optimum batch RT 15 was performed at $25^{\circ} \mathrm{C} / 65 \% \mathrm{RH}$ and $40^{\circ} \mathrm{C} / 75 \% \mathrm{RH}$ storage conditions up to 3 months. As per the stability plan, the patches were withdrawn and tested for appearance, $\%$ assay of drug content, related substances, in vitro adhesion, and cold flow. Stability results at controlled room temperature (CRT) and accelerated storage condition were found to be satisfactory for up to 3 months.

\section{Discussion}

In the present investigation, we have developed rotigotine TDS using dot matrix technology. Rotigotine patches were prepared using solved casting method. First of all, preformulation studies were carried out to select backing film, release liner, PSA, drug loading capacity in various PSAs. Solubility of rotigotine was found $73.5 \mathrm{mg} / \mathrm{mL}$, $20 \mathrm{mg} / \mathrm{mL}$, and $12.8 \mathrm{mg} / \mathrm{mL}$ in propylene glycol, oleyl alcohol, and isopropyl palmitate, respectively. Rotigotine is freely soluble in ethanol and ethyl acetate. Drug excipient compatibility study did not show any significant change in assay and related substances, so rotigotine is compatible with various PSAs (DT-6908, DT-2054, and Bio PSA-4302) and permeation enhancers. For crystallization study, various patches were prepared with different drug concentrations in different PSAs. There was no crystal found in DT-2054 and Bio PSA 4302 up to 9\% drug concentration in the presence of povidone K29/32. Backing film Scotchpak 9730 and release liner SP-1022 was not showing any transmission and uptake of rotigotine. Ratio of silicone and acrylate adhesive polymer was optimized by checking physical compatibility, and it is found to be compatible with 9:1 ratio of silicone and acrylate polymer. A CCD was selected for the optimization of the formulation. Silicone adhesive concentration (X1), povidone K29/32 concentration (X2), and propylene glycol concentration (X3) were selected as independent variables. The peel $(\mathrm{g} / \mathrm{mm})$, tack $\left(\mathrm{g} / \mathrm{mm}^{2}\right)$, shear (minutes), and flux $\left(\mu \mathrm{g} / \mathrm{cm}^{2} /\right.$ $\mathrm{hr}$ ) were selected as dependent variables to define design space. Impact of factor X1, X2, and X3 on peel $(\mathrm{g} / \mathrm{mm})$, tack $\left(\mathrm{g} / \mathrm{mm}^{2}\right)$, shear (minutes), and flux $\left(\mu \mathrm{g} / \mathrm{cm}^{2} / \mathrm{hr}\right)$ were evaluated based on ANOVA results, contour plots, and 3D surface plots. For response: peel, it can be concluded that the individual factor X1: silicone adhesive concentration had a positive effect on peel strength of patch because of higher concentration of silicone polymer increases the peel, whereas factor X2: povidone K29/32 concentration had a negative effect on peel strength of patch because a higher amount of povidone K29/32 decreases the peel. Peel strength of patch is adhesive strength of patch, thus, adding silicone polymer increases the adhesive strength of patch, and povidone decreases the adhesion strength (Fig. 2). ${ }^{[28,29]}$ For response: tack, it can be concluded that the individual factor X1: silicone adhesive concentration and factor X3: propylene glycol concentration had a positive effect on tack strength of patch because of higher concentration of silicone polymer and propylene glycol increases the tack, whereas factor X2: povidone K29/32 concentration had a negative effect on tack strength of patch because higher amount of povidone K29/32 decreases the tack (Figs 3 and 4). It is well known that an increase in PSA concentration increases the tack value of patch. Permeation enhancer (propylene glycol) has plasticizer effect due alteration of Tg value of the PSA of the system, so increase in tack value. For response: shear, it can concluded that the individual factor X1: silicone adhesive concentration and factor X2: povidone K29/32 concentration had a positive effect on shear strength of 
patch because of higher concentration of silicone polymer and povidone K29/32 increases the shear, whereas factor X3: propylene glycol concentration had negative effect on shear strength of patch because a higher amount of propylene glycol concentration decreases the shear (Figs 5 and 6). ${ }^{[30]}$ Shear strength of patch is cohesive strength of patch. An increase in silicone polymer and povidone increase the cohesive strength of patch while permeation enhancer (propylene glycol) decreases the cohesive strength as it has plasticizing effect. For response: flux, it can concluded that the individual factor X1: silicone adhesive concentration had a negative effect on permeation rate of patch because of higher concentration of silicone polymer decreases the permeation rate, whereas factor X3: propylene glycol concentration and factor X2: povidone K29/32 concentration had positive effect on permeation rate of patch because higher amount of propylene glycol concentration and povidone K29/32 increases the permeation rate (Figs 7 and 8 ). ${ }^{[31]}$ The diffusion coefficient of the drug is reduced within the system when the concentration of PSA increases. Thus, flux was reduced when polymer concentration increases. Permeation enhancers can enhance the delivery of drug through skin by various mechanisms. Thus, an increase in propylene glycol concentration increases the delivery rate. Various pieces of literature support the positive effect of povidone on the delivery rate of the drug. From the graphical optimization of measured responses (overlay plot), formulation with $80 \%$ silicone adhesive concentration, $3 \%$ povidone concentration, and $4.5 \%$ propylene glycol concentration, were found to be optimum formulation. Finally, optimized formulation was evaluated for appearance, weight of matrix, thickness of patch, $\%$ assay of drug, adhesion properties, like peel, tack and shear, cold flow, and ex vivo permeation study. All parameters were found satisfactory for optimum formulation. Optimum formulation showing good wear properties, like peel $(32.5 \pm 1.07 \mathrm{~g} / \mathrm{mm})$, tack $\left(14 \pm 0.89 \mathrm{~g} / \mathrm{mm}^{2}\right)$, and shear $(105 \pm 2.61)$, and permeation rate $\left(8.10 \pm 0.51 \mu \mathrm{g} / \mathrm{cm}^{2} / \mathrm{hr}\right)$. From Fig. 9, $C_{\max }$ achieved within 12 hours, and the rate of permeation maintains up to 24 hours, and then starts decreasing. Optimum formulation also found stable, based on stability study.

\section{CONCLUSION}

Rotigotine drug in an adhesive patch was developed using novel dot matrix technology to maintain delivery up to 3 days along with good wear properties. Various preformulation study studies, like solubility study, drug-excipient study, crystallization study, uptake study, transmission study, and optimization silicone-acrylate polymer ratio were performed. Based on the crystallization study, it was found that crystal inhibitor is required to develop rotigotine TDS. Backing film Scotchpak 9730 and release liner Scotchpak-1022 was selected based on transmission and uptake study of rotigotine. CCD was used to understand the effect of various factors, like silicon adhesive concentration, povidone concentration, and propylene glycol concentration on in vitro adhesion testing and ex vivo permeation study. Silicon adhesive has a positive impact on peel strength, tack strength, and shear strength of patch and negative impact on permeation rate. Similarly, povidone K29/32 has positive impact on shear and permeation rate of patch, and propylene glycol has positive impact on tack strength and permeation rate of the developed patch. Optimum formulation contains $80 \%$ silicone adhesive, 3\% povidone K29/32, and $4.5 \%$ propylene glycol showing good wear properties, like peel $(32.5 \pm 1.07 \mathrm{~g} / \mathrm{mm})$, tack $\left(14 \pm 0.89 \mathrm{~g} / \mathrm{mm}^{2}\right)$, shear $(105 \pm 2.61)$, and permeation rate $\left(8.1 \pm 0.51 \mu \mathrm{g} / \mathrm{cm}^{2} / \mathrm{hr}\right)$. Optimized formulation was stable up to 3 months, and not showing any significant changes for appearance, $\%$ assay of drug content, related substances, in vitro adhesion, and cold flow. Thus, present research work confirms the development of rotigotine TDS, using novel dot-matrix technology with good wear properties and permeation rate up to 72 hours.

\section{AbBreviations}

CCD: Central composite design, DoE: Design of experiment, TDS: Transdermal system, PSA: Pressure sensitive adhesive, USA: United States of America, HPLC: Highperformance chromatography, GSM: Grams per square meter, BDS: Base deactivated silica, RP-HPLC: Reversephase high-performance liquid chromatography, DT: Durotak, SP: Scotchpak, RH: Relative humidity.

\section{REFERENCES}

1. Guy RH, J Hadgraft. Transdermal Drug Delivery. Marcel Dekker Inc, New York, Edition 2; 2003. p. 371-377.

2. Roy C, Gandhi A. Formulation aspects, approaches and evaluation of transdermal drug delivery system: a concise review. Indian Research Journal of Pharmacy and Science. 2017;4:963-971. DOI: 10.21276/irjps.2017.4.2.3

3. Agrahari S, Sharma A, Kumar S, Sharma A, Sagar MK. Formulation and development of transdermal patches of piroxicam. Asian Journal of Pharmaceutical Research and Development. 2019;7:119-128. DOI: 10.22270/ajprd.v7i3.511

4. Pastore MN, Kalia YN, Horstmann M, Roberts MS. Transdermal patches:history, development and pharmacology. British Journal of Pharmacology. 2015;172:2179-2209. DOI: 10.1111/bph.13059

5. Keservani RK, Bandopadhyay S, Bandyopadhyay N, Sharma AK. Design and fabrication of transdermal/skin drug-delivery system. Drug Delivery Systems. Academic Press, 2020:131-178.

6. Jhawat V, Saini V, Shah AF, Sharma PK, Monika. Dot matrix-a novel technique fortransdermal drug delivery. Paper presented at the 4th National Conference on Analytical skill development inPharmaceutical Research, Punjab Technical University, CT Institute of Pharmaceutical Sciences, Jalandhar.

7. Wiedersberg S, Guy RH. Transdermal drug delivery: 30+ years of war and still fighting! Journal of Controlled Release. 2014;190:150-156. DOI: 10.1016/j.jconrel.2014.05.022

8. Kopper NW, Gudeman J, Thompson DJ. Transdermal hormone therapy in postmenopausal women: a review of metabolic effects and drug delivery technologies. Drug Design, Development and Therapy. 2008;2:193-202. DOI: 10.2147/dddt.s4146 
9. Hadgraft J, Lane ME. Passive transdermal drug delivery systems. American Journal of Drug Delivery. 2006 Sep 1;4(3):153-160. DOI: 10.2165/00137696-200604030-00003

10. Hossain M, Quebe-Fehling E, Sergejew T, Schmidt G, Skerjanec A, Cohen A, et al. Comparative bioequivalence studies with Estradot ${ }^{\circledR}$ and Menorest $\AA$ transdermal systems. Maturitas. 2003;46:187-198. DOI: 10.1016/S0378-5122(03)00190-7

11. Reynolds NA, Wellington K, Easthope SE. Rotigotine In Parkinson's Disease. CNS Drugs. 2005;19:973-981. DOI: 10.2165/00023210200519110-00006

12. Sanford M, Scott LJ. Rotigotine Transdermal Patch. CNS Drugs. 2011;25:699-719. DOI: 10.2165/11206750-000000000-00000

13. Shingade GM, Aamer Q, Sabale PM, Grampurohit ND, Gadhave MV, Jadhav SL, et al. Review on recent trend on transdermal drug delivery system. Journal of Drug Delivery and Therapeutics. 2012;2:66-75. DOI: $10.22270 / j d d t . v 2 i 1.74$

14. Kriplani P, Sharma A, Aman PP, Chopra B, Dhingra A, Deswal G. Formulation and evaluation of transdermal patch of diclofenac sodium. Global Journal of Pharmacy and Pharmaceutical Sciences. 2018;4:1-4. DOI: 10.19080/GJPPS.2018.04.555647

15. Amnuaikit C, Ikeuchi I, Ogawara KI, Higaki K, Kimura T. Skin permeation of propranolol from polymeric film containing terpene enhancers for transdermal use. International Journal of Pharmaceutics. 2005;289:167-178. DOI: 10.1016/j.ijpharm. 2004.11.007

16. Swarupa PG, Krishna DR, Prasad KRS, Babu KS. Stability indicating method development and validation for the estimation of rotigotine by RP-HPLC in bulk and pharmaceutical dosage form. Oriental Journal of Chemistry. 2015;31:2499-2505. DOI: 10.13005/ojc/ 310486.

17. Cilurzo F, Gennari CG, Minghetti P. Adhesive properties: a critical issue in transdermal patch development. Expert Opinion on Drug Delivery. 2012;9:33-45. DOI: 0.1517/17425247.2012.637107

18. Rudawska A. Pressure-Sensitive Adhesive Joints. Adhesives and Adhesive Joints in Industry. Intech Open 2019.

19. Gutschke E, Bracht S, Nagel S, Weitschies W. Adhesion testing of transdermal matrix patches with a probe tack test-In vitro and in vivo evaluation. European Journal of Pharmaceutics and Biopharmaceutics. 2010;75:399-404. DOI: 10.1016/j.ejpb. 2010.03.016

20. Krishnaiah YS, Yang Y, Hunt RL, Khan MA. Cold flow of estradiol transdermal systems: influence of drug loss on the in vitro flux and drug transfer across human epidermis. International Journal of Pharmaceutics. 2014;477:73-80. DOI: 10.1016/j.ijpharm.
2014.10.013

21. Wokovich AM, Strasinger C, Kessler J, Cai B, Westenberger B, JhongRM, et al. Cold flowmeasurement of transdermal drug delivery systems (TDDS). International Journal of Adhesion and Adhesives. 2015;59:71-76. DOI: 10.1016/j.ijadhadh.2015.02.002

22. Krishnaiah YS, Katragadda U, Khan MA. Stereomicroscopic imaging technique for the quantification of cold flow in drug-inadhesive type of transdermal drug delivery systems. Journal of Pharmaceutical Sciences. 2014;103:1433-1442. DOI: 10.1002/jps. 23915

23. Ameen D, Michniak-Kohn B. Development and in vitro evaluation of pressure sensitive adhesive patch for the transdermal delivery of galantamine: effect of penetration enhancers and crystallization inhibition. European Journal of Pharmaceutics and Biopharmaceutics 2019;139:262-271. DOI: 10.1016/j.ejpb. 2019.04.008

24. Mohammed D, Matts PJ, Hadgraft J, Lane ME. In vitro-in vivo correlation in skin permeation. Pharmaceutical Research. 2014;31:394-400. DOI: 10.1007/s11095-013-1169-2

25. Abd E, Yousef SA, Pastore MN, Telaprolu K, Mohammed YH, Namjoshi S, et al. Skin models for the testing of transdermal drugs. Clinical Pharmacology: Advances and Applications. 2016;8:163-176. DOI: $10.2147 / C P A A . S 64788$

26. Vora C, Patadia R, Mittal K, Mashru R. Risk based approach for design and optimization of stomach specific delivery of rifampicin. International Journal of Pharmaceutics. 2013;455:169-181. DOI: 10.1016/j.ijpharm.2013.07.043

27. Vora CN, Patadia R, Mittal K, Mashru RC. Risk based approachfor design and optimization of site specific delivery of isoniazid Journal of Pharmaceutical Investigation. 2014;45:249. DOI: 10.1007/ s40005-014-0170-z

28. Benedek I: Pressure-Sensitive Adhesives and Applications. Marcel Dekker inc, New York, Second Edition 2004.

29. Minghetti P, Cilurzo F, Tosi L, Casiraghi A, Montanari L. Design of a new water-soluble pressure-sensitive adhesive for patch preparation. AAPS PharmSciTech. 2003;4:53-61. DOI: 10.1208/ pt040108

30. Benedek I: Development in Pressure-Sensitive Products. CRC Press, Second Edition 2019.

31. Shabbir M, Ali S, Farooq M, Adnan S, Yousaf M, Idrees A, et al. Formulation factors affecting in vitro and ex vivo permeation of bisoprolol fumarate from a matrix transdermal patch. Advances in Polymer Technology. 2016;35:237-247. DOI: 10.1002/ adv.21546

HOW TO CITE THIS ARTICLE: Prajapati ST, Mandli V. Formulation development of rotigotine transdermal system using dot-matrix technology. Int. J. Pharm. Sci. Drug Res. 2020;12(4):404-414. DOI: 10.25004/IJPSDR.2020.120414 